\title{
A RECONVERSÃO DO SOCIAL dilemas da redistribuição no tratamento focalizado
}

\author{
Anete Brito Leal Ivo
}

\begin{abstract}
Resumo: Este artigo caracteriza o processo de reconversão da questão social no Brasil no contexto do projeto neoliberal. Analisa o processo de despolitização da questão social contemporânea, por meio das políticas sociais focalizadas num quadro dissociado da proteção e dos direitos. Explicita as fragilidades desse modelo no plano institucional, societário e político, bem como os efeitos na segmentação da exclusão, aprofundando um conflito redistributivo de base, entre pobres e quase-pobres.

Palavras-chave: políticas sociais focalizadas; pobreza; Brasil.
\end{abstract}

\begin{abstract}
This article characterizes the process of re-conversion of the social question in Brazil in the context of the neo-liberal project. It analyses the process of depoliticization of the contemporary social question, through the focused social politics in an independent scheme of protection and rights. It emphasizes not only the fragility of such model in the institutional, social and political plans, but also the effects of the segmentation of exclusion, increasing the distributive conflict, between the poor and the almost poor.

Key words: focused social politics; poverty; Brazil.
\end{abstract}

A política social é uma dimensão necessária da democracia nas sociedades modernas e está estreitamente ligada aos valores da eqüidade que fundam a legitimidade política e a concepção que as sociedades e os governos têm do seu projeto político e de seu destino.

No quadro institucional, as políticas sociais integram um sistema de ação complexo resultante de múltiplas causalidades e diferentes atores e campos de ação social e pública: proteção contra riscos; combate à miséria; desenvolvimento de capacidades que possibilitem a superação das desigualdades e o exercício pleno da cidadania; redistribuição de riquezas; etc. Assim, elas são dispositivos institucionais criados com o objetivo de assegurar a cada um as condições materiais de vida que permitam ao cidadão exercer seus direitos sociais e cívicos. Atuando no âmbito redistributivo, elas envolvem necessariamente relações de poder e são, portanto, conflitivas e qualificadoras da democracia e do projeto de inclusão social das sociedades. ${ }^{1}$

Neste sentido, as políticas sociais se articulam necessariamente com a dinâmica do crescimento e são condicionadas pela natureza das relações entre capital e trabalho, estando diretamente relacionadas às tendências que conformam a dinâmica do mercado de trabalho em cada sociedade - principal mecanismo de inclusão social. Ou seja, não se pode compreender os dilemas da política social fora da dimensão do trabalho, entendido como a forma concreta de reprodução e inserção social e como valor histórico e culturalmente instituído, que confere identidade social e matriz de sociabilidade no marco de uma construção coletiva. Em outras palavras, as políticas sociais estão associadas a processos civilizatórios que definem as possibilidades de construção dos vínculos e do contrato social. Contudo, partindo de diagnósticos equivocados, podem constituir-se em antipolíticas, desde que seus resultados aprofundem as desigualdades e reduzam a capacidade redistributiva que toca o conjunto da sociedade.

Assim, a nebulosidade das polêmicas e análises relativas às políticas sociais guardam estreita relação com a construção da política num sentido mais amplo e expressa clivagens ideológicas que orientam as alternativas e opções de diferentes atores diante do projeto político e 
de desenvolvimento nacionais, no confronto com as perspectivas do neoliberalismo econômico que entende "mercado" como o melhor regulador das relações sociais.

Neste artigo, procura-se caracterizar o processo de reconversão profunda dos sentidos e alcances do novo tratamento da questão social no contexto de hegemonia de um projeto neoliberal, analisando a natureza e as ambigüidades dessa transição num país historicamente marcado pelas elevadas taxas de desigualdades, como o Brasil, e os efeitos que o tratamento focalizado das políticas sociais, tomadas como eixo central de enfrentamento da pobreza, traz para o conjunto da sociedade brasileira, sobretudo se confrontado ao projeto de inclusão social universalista desenhado na Carta Constitucional de 1988.

A idéia central que norteia a presente análise é a de que as mudanças que orientam o conjunto das políticas sociais atualmente objetivam, por um lado, reduzir os efeitos adversos do ajuste estrutural (têm, portanto, caráter compensatório) e, por outro, se implantarem à margem da institucionalidade vigente no campo da proteção social (neste sentido, possuem natureza flexível e não se constituem em direitos). Esta tendência contraria os ganhos democráticos e o projeto de sociedade pactuado entre elites e trabalhadores no quadro Constitucional, gerando problemas de governabilidade ${ }^{2}$ e uma profunda dissocialização na sociedade brasileira. Este artigo busca esclarecer algumas dessas questões a partir da análise dos alcances da política focalizada no quadro atual.

\section{O CONTEXTO CONTEMPORÂNEO}

\section{A Natureza do "Social" na Modernidade: a "Desmercantilização" ${ }^{3}$ Parcial da Força de Trabalho}

O "social" constituiu-se, historicamente, como registro da modernidade, centrado e estruturado em torno do trabalho. A centralidade do trabalho na organização das sociedades contemporâneas ligava-se, por um lado, à capacidade do movimento operário de integrar e articular interesses mais amplos da sociedade e, por outro, à capacidade do Estado em regular o conflito dos interesses divergentes.

No âmbito institucional, passou-se de um regime baseado na responsabilidade individual e fundado no direito civil para um regime de solidariedade assentado num contrato social e fundado na noção de direito social (Ewald, 1986), através de um conjunto de leis relacionadas às condições do trabalho e à proteção aos trabalhadores que perderam a capacidade do uso da força de trabalho (doenças, invalidez, desemprego, velhice, acidentes, etc.), reconvertendo uma noção de responsabilidade, antes restrita ao âmbito individual, para uma noção objetiva de proteção social. ${ }^{4}$ Ou seja, o direito social criou as condições de intervenção crescente do Estado na prevenção de perigos que ameaçam a sociedade, consolidando o princípio de uma responsabilidade pública institucionalizada.

Da mesma forma, no contexto do pós-guerra, a estruturação das políticas sociais constituiu-se na resposta histórica ao dilema de organização dos interesses privados no contexto do interesse público, em torno de uma política da redistribuição de riqueza. As mediações historicamente construídas pelo Direito, pela justiça e pelas políticas sociais resultaram na governabilidade gerada contra a influência desorganizadora do mercado.

A tensão permanente entre a organização da defesa da sociedade (que contou com o apoio das classes trabalhadoras) e a regulação dos mercados estruturou as sociedades modernas, tendo nos Estados nacionais modernos a versão institucional dessa regulação e na matriz salarial a norma definidora das condições de identidade e de sociabilidade da classe trabalhadora, base de sua cidadania.

Desta perspectiva, o "social" refere-se a um conjunto de mediações que se estabelecem entre três ordens: a econômica, a política e a doméstica, como afirmam Théret (1992) e Lautier (1999). Entendidas no sentido amplo tanto o direito social como as contribuições sociais - a transferência e a distribuição de bens e serviços gratuitos são mediações jurídicas, monetárias e de serviços (públicos) que recobrem todo um sistema de direitos e obrigações entre os cidadãos e o Estado. Estes direitos e obrigações têm um forte componente arbitrário e dependem do contexto cultural e histórico em que se inscrevem. Desta perspectiva, tanto as políticas sociais como os direitos sociais representam uma desmercantilização do trabalho parcial (Esping-Andersen, 1990), resultante da força do movimento sindical dos trabalhadores no período do pósguerra.

A perspectiva neoliberal, no entanto, parte do suposto de que é impossível a preservação das regras que orientam a política social no marco da concepção do Estado de Bem-Estar Social, dada a crise fiscal, a excessiva intervenção do Estado no mercado e os possíveis estímulos negativos que os dispositivos institucionais geram no âmbito do comportamento dos indivíduos, alimentando, supostamente, comportamentos morais indesejáveis, como "possível parasitismo dos trabalhadores às custas do es- 
forço das coletividades e/ou o uso clientelístico nas transações". Assim, a única via de retomada do crescimento da economia seria, por esta visão, romper a articulação entre "emprego e proteção social", sacrificando o "social" (a proteção social, a política de salário mínimo, etc.). $\mathrm{O}$ desenho da nova política de redistribuição no quadro neoliberal pressupõe, portanto, a distensão da relação entre proteção social e emprego, rompendo o modelo que caracterizou a construção do Estado social.

Isto implica que a renda não seja mais indexada sobre o emprego ocupado. O centro dessa mudança situa-se na ruptura da proteção através das reformas da Previdência, ${ }^{5}$ afetando fundamentalmente os direitos dos trabalhadores protegidos, ${ }^{6}$ e na reorientação da universalidade para a operação de diferentes programas estratégicos e compensatórios da assistência focalizada na linha da pobreza segundo diferentes "públicos-alvo".?

\section{Ciclos de Tratamento do Conflito Social no Brasil}

A retomada da questão da pobreza como prioridade da agenda política no Brasil, no final da década de 90, emerge no curso de um processo conflitivo de mudanças, no qual distinguem-se três movimentos e conjunturas distintas nas relações entre Estado e sociedade, que expressam movimentos de hegemonia e contra-hegemonia entre atores multilaterais e atores nacionais e locais, determinando limites e desafios ao Estado nacional e à ação pública, especialmente quanto ao tratamento da questão social.

A primeira etapa (1970-1980) expressou-se pela luta democrática de abertura política e de explosão de movimentos reivindicativos pelos direitos dos cidadãos, especialmente nas áreas urbanas. Duas forças fundamentais conduziram este processo: o novo sindicalismo e os movimentos sociais, além de uma explosão de redes associativas que canalizavam demandas, expressando-se por meio de diversas arenas públicas e pela via da representação legislativa. Essas mudanças culminaram com a instalação da Assembléia Nacional Constituinte e a conseqüente promulgação da Constituição de 1988. Este quadro constitucional inovou o tratamento da política social como política de inclusão social de caráter universalista e de extensão dos direitos sociais às camadas mais pobres da população, associadas ao resgate da cidadania e à sua universalização, sob a égide da Seguridade Social, que, como dizem Theodoro e Delgado (2003), "estão longe de se constituírem mecanismos de transferência de renda para pobres e carentes".
A segunda etapa, a dos ajustes institucionais da década de 90, representou um momento de interferência autoritária do Estado nacional sobre as conquistas trabalhadoras, dando prosseguimento a uma agenda de reformas do Estado (crise fiscal, redução das responsabilidades sociais do Estado, etc.). O resultado do processo de ajuste do Estado reforçou o Executivo e atribuiu alto peso às tecnocracias na tomada de decisões, especialmente aquelas vinculadas às áreas estratégicas da economia e da política tributária, centrais ao jogo dos ajustes.

Este momento representa uma vivência controvertida da democracia, no qual o regime, ao mesmo tempo em que se reafirma como valor moral, se expressa, na prática, pela desregulação dos direitos sociais, afetando, portanto, as condições de inclusão social e de participação da comunidade nacional pela via do trabalho. Em vez de possibilitar maior integração social, gerou, na prática, mais exclusão, fomentando a perda de sentidos da organização da vida coletiva e menor credibilidade e confiança na política, que, para alguns, reaparece como espaço de privilégios e de desordem social, estimulando, muitas vezes, a anomia.

$\mathrm{Na}$ terceira etapa, que se consolida sobretudo no final da década de $90,{ }^{8}$ reconhece-se que a estabilização é importante, mas absolutamente insuficiente. Observamse os limites perversos da ação imperiosa da desregulação autoritária e a urgência de ações que contemplem formas de integração social como prioridade, equacionadas de forma fragmentada através de diversos programas compensatórios de enfrentamento da pobreza, descentralizados e operados em parceria com a sociedade civil, na qual ganha importância o papel das organizações nãogovernamentais do chamado Terceiro Setor. As alternativas para esta política são diversas e, longe de configurarem consenso, expressam, pelo contrário, um enorme campo de controvérsias de sentidos da ação e dos objetivos.

Do ponto de vista governamental, no entanto, o debate restringe-se tecnicamente às "escolhas públicas eficientes" em face da restrição dos gastos sociais. Isto significa desenvolver uma inteligência estratégica que intervenha na política social nos limites dos ajustes econômicos, o que na prática implica contrapor as políticas de assistência às de proteção e dar flexibilidade e contingenciamento aos benefícios da assistência, o que se contrapõem ao sentido mais amplo da justiça redistributiva e da responsabilidade pública. Em vez de enfrentar o problema pelas suas causas (estruturais), a po- 
lítica social orienta a ação pelos seus efeitos, ou seja, o combate à pobreza, subordinando a ética da solidariedade institucional e responsabilidade pública do Estado à contabilidade dos gastos. ${ }^{9}$

\section{Uma Transição Complexa: as Contradições entre Inclusão Política e Exclusão Social}

Este processo de transição contém um paradoxo da sociedade brasileira no contexto atual, caracterizado por uma inversão entre o regime político democrático conquistado, que tende a incluir politicamente e ampliar a cidadania, e a dinâmica de uma economia dessocializada, que historicamente produziu as maiores taxas de desigualdades socioeconômicas e hoje levou massivamente à exclusão, negando a cidadania pela destituição dos direitos sociais mínimos num quadro recessivo e de desemprego crescente.

A clivagem entre inclusão e exclusão, em face dos direitos sociais constitucionalmente reconhecidos, possibilita analisar o campo de atuação e o grau de segurança ou incerteza das políticas sociais, que podem ser agrupadas em três núcleos que configuram tipos de direitos distintos: $:^{10}$

- aquelas que respondem pelos direitos sociais básicos estruturados no aparelho do Estado; ${ }^{11}$

- alguns programas que respondem pela garantia dos direitos sociais previstos na Constituição, mas que dependem da opção dos governos por meio de programas estruturais - são vinculados constitucionalmente mas não estão protegidos de cortes; ${ }^{12}$

- e aqueles programas emergenciais voltados para o enfrentamento de carências e situações de vulnerabilidade social de segmentos específicos. Apresentam caráter transitório e sua continuidade dependente, essencialmente, das opções de governo, atendendo a uma demanda difusa e não estruturada no aparelho do Estado. ${ }^{13}$

Essa ambivalência entre inclusão e exclusão, bem como suas contradições, funda um dos principais dilemas da governabilidade no Brasil, país com uma das mais elevadas taxas de desigualdades: manter a ordem jurídica e política baseada no princípio da igualdade básica entre cidadãos, num contexto de ampliação dos direitos políticos, abalados pelas inúmeras desregulações dos direitos sociais, redefinição de compromissos pactuados e aprofundamento das desigualdades no acesso à distribuição de riqueza e aos bens públicos.

\section{DE UM PROJETO CONSTITUCIONAL INCLUSIVO PARA UMA ASSISTÊNCIA MITIGADORA}

\author{
A Reversão da Perspectiva Constitucional \\ do Estado Social Inclusivo
}

No eixo de encaminhamento desse dilema, observa-se a reconversão do tratamento da "questão social" no Brasil, de uma dimensão de política de inclusão social universalizada e de proteção, voltada para a produção de justiça social, para centrar-se sobre seus efeitos, ou seja, em programas mitigadores, setorializados e focalizados da pobreza.

Na visão universalista das políticas sociais, o mercado é o objeto do embate distributivo, o que supõe um papel decisivo e regulador do Estado. ${ }^{14}$ A perspectiva focalizada abandona a dimensão da universalidade inclusiva e faz a opção pela "gestão estratégica da pobreza", num ambiente adverso à mudança. Este novo paradigma, entretanto, supõe o fortalecimento da capacidade dos pobres para lutarem contra pobreza, ${ }^{15}$ como sujeitos deste processo, o que significa que o encaminhamento da erradicação da pobreza supõe considerar também variáveis políticas e societais no controle e implantação dessas políticas pelos seus usuários, bem como a construção de arenas concertadas com atores sociais locais.

Ou seja, no contexto atual, desloca-se o centro da política social de uma dimensão de redistribuição da riqueza (imperfeita e inconclusa) para o tratamento compensatório dos seus efeitos (o controle parcial e mitigador da miséria). Como analisa Lautier (1999), desvinculando a pobreza dos seus determinantes estruturais, separam-se os indivíduos submetidos a essa condição dos seus lugares no sistema produtivo (como projeto ou como perda). Assim, o diagnóstico da erradicação da pobreza desvincula o sistema de proteção social, dos direitos sociais, passando a assistência a constituir um atributo individual para aqueles que "moralmente" têm direito ou potencialidade para se desenvolverem.

Conforme apresentado em Ivo (2001), esta reconversão da questão social para o âmbito exclusivo da assistência subordinada à tese da eficiência dos gastos sociais tende a despolitizar e tecnificar a questão social, transformando direitos sociais (universais) em programas e medidas técnicas ou estratégicas de distinguir, contar e atribuir benefícios a um conjunto de indivíduos selecionados pelos inúmeros programas sociais focalizados, sem se constituir em direitos. Ademais, além de alterar a pers- 
pectiva política constitucional, dilui o princípio do direito à racionalidade técnica do gasto público.

Opera-se, portanto, uma ruptura estrutural entre os planos social, econômico e político, através de um processo de transição que prioriza o tratamento da questão social com base em um novo modelo de assistência ${ }^{16}$ focalizado. A transição desse processo compreende:

- um processo de desconstrução (a retórica da crise) simbólica e ideológica dos sistemas de seguridade anteriores, por meio da ruptura entre trabalho e proteção e da centralidade do equacionamento da questão social restrito à eficiência do gasto público, pela qual opera-se a transfiguração dos direitos de proteção por ações de assistência e a política redistributiva em gestão técnica do social.

- a centralidade do tratamento da inserção dos indivíduos ao mercado, através de transferências monetárias, estimulando o consumo e a demanda de serviços de assistência, rompendo a dimensão de solidariedades coletivas mais amplas;

- uma organização e mobilização da sociedade civil e dos próprios pobres na construção e controle dos programas, por meio de parcerias entre Estado e sociedade civil.

Esta transição tem levado alguns analistas a entenderem a situação que se aprofunda na segunda metade dos anos 90 como mais uma "década perdida", mais problemática que o contexto da década de 80, que, apesar da crise inflacionária, expressou ganhos políticos no aperfeiçoamento democrático e na construção de um projeto de transformação social e política para o país. O quadro recessivo do presente repercutiu sobre as possibilidades de enfrentamento da pobreza e da indigência, que atualmente apresenta novos contornos ${ }^{17}$ e cuja avaliação não pode deixar de considerar a qualidade do crescimento, as responsabilidades reguladoras do Estado e o compromisso ético do desenvolvimento inclusivo e sustentado.

\section{Uma Circularidade sem Saída: a Natureza das Políticas Sociais Focalizadas}

A reorientação da política social centrada no combate à pobreza aparece, então, neste contexto, com o objetivo de reduzir os efeitos adversos dos ajustes estruturais e da reestruturação produtiva, institucionalizando-se à margem do campo da proteção social. Esta mudança se faz através do paradigma da focalização da política social no encaminhamento da questão do combate à pobreza e à desigualdade.
A focalização como princípio ordenador das políticas sociais é um conceito que se situa numa instância principalmente instrumental e operativa, relacionada à seletividade do gasto social. Focalizar é estabelecer mecanismos e critérios idôneos para delimitar "quem" tem direito aos serviços básicos que se outorgam como subsídio público (Candia, 1998). Assim, a focalização constitui um componente básico e permanente para a formulação de uma política social "racional" (estratégica), no marco de economias abertas e competitivas. São políticas dirigidas às áreas consideradas "brandas", ou seja, que não comprometam nenhum aspecto da reforma estrutural. Portanto, estão deslocadas da institucionalidade da proteção social. A sua operacionalização enfatiza: a diferenciação de acesso; o subsídio à demanda; a focalização da população; a descentralização das ações; e a governança, ou seja, a mobilização de atores sociais e políticos numa ação concertada segundo objetivos e metas dos programas.

Este modelo se orienta por três paradigmas:

- o primeiro, de natureza institucional-estratégica, diz respeito a uma racionalidade institucional e à eficácia da operacionalização da política social pela via da focalização do atendimento, o que envolve o desenvolvimento constante de novas "tecnologias" de medição da "populaçãoalvo" dos programas, a partir de diferentes centros de operação do tecido social em situação de vulnerabilidade (Candia, 1998; Fleury, 1998; Lautier, 1999);

- o segundo integra-se aos objetivos próprios a uma racionalidade econômica, sob hegemonia do mercado, e implica a transferência monetária direta aos beneficiários, estimulando as condições de sua integração ao mercado, como consumidores e/ou pequenos empreendedores, ${ }^{18}$ e à falta de políticas estruturais mais amplas de crescimento;

- o terceiro, de caráter societal, envolve a definição de responsabilidades partilhadas entre Estado e sociedade civil (parcerias) e a descentralização das ações no âmbito local, supondo os pobres como sujeitos políticos ativos.

Do ponto de vista de uma percepção positiva dessas políticas, alguns agentes reconhecem a contribuição que alguns desses programas podem exercer no aumento do impacto sobre os beneficiados; outros reconhecem uma relação mais favorável do custo-benefício desses programas; outros, ainda, observam como a identificação do problema e a adequação de soluções diferenciais, ajustadas ao perfil dos beneficiados, são mais eficazes. Outros reconhecem a importância desses programas apenas em cir- 
cunstâncias emergenciais e recessivas, ou, ainda, quando acompanhados por políticas de vocação universal. Finalmente, alguns identificam um impacto dos programas na melhoria do consumo da população beneficiada, num quadro de profunda miséria e indigência, aliviando as condições de reprodução mínima dessas populações.

\section{A Reconversão dos Sentidos da Solidariedade Institucional e o Aprofundamento das Fraturas Sociais}

O caráter fragmentado da incorporação de diferentes segmentos das classes trabalhadoras ao sistema (baseado na atribuição do direito social, restrito à camada assalariada) gerou uma conversão perversa de benefícios-obrigações dos segurados em supostos privilégios. Hoje, o que é dever de proteção do Estado (para todos) reconverte supostamente os segurados (de forma perversa) em indivíduos-perversos-imorais ao sistema, atribuindo-lhes então a responsabilidade pela miséria dos outros. Ou seja, por meio de uma operação de reconversão simbólico-ideológica, deslocam-se a insuficiência e a fragilidade do Estado social, ou a opção restrita da ação do Estado em matéria de assistência, para a responsabilidade individual dos que a ele acederam. Segmentos da classe média (assalariados dos setores público e privado) são ao mesmo tempo vítimas e bandidos de um sistema inconcluso. A base desse raciocínio são os cálculos matemáticos da contribuição/benefício da perspectiva individual e não o papel e a responsabilidade social do Estado. Com isso, dilui-se a compreensão dos determinantes estruturais da crise e tomam-se os efeitos por causas (Ivo, 2001), optando por um acirramento do conflito distributivo na basemuito bem levantado por Theodoro e Delgado (2003) -, que contrapõe pobres desprotegidos aos menos pobres.

No âmbito do tratamento da questão "social", retira-se o caráter universalista dos direitos, passando-se gradativamente a uma individualização da ação pública segundo atributos pessoais (dos mais aptos). A formação de um sistema dual, de proteção e assistência, cria irracionalidades na coordenação do sistema. A definição da assistência aos mais necessitados tem caráter restritivo, voltado para aqueles que não possuem qualquer chance de integrar os circuitos produtivos nem a redistribuição contratuais, de acordo com a Lei Brasileira de Assistência, de dezembro de 1993, conforme analisa Lautier (1999).

No plano da cidadania, esta individualização das responsabilidades gera uma inversão no binômio clássico entre direitos e obrigações que organiza a relação entre
Estado e cidadãos. A responsabilidade dos indivíduos não criaria necessariamente direitos construídos e pactuados na esfera da vida coletiva, o que contribui para a ruptura dos vínculos contratuais de um Estado democrático, gerando tensões de governabilidade e resistências cívicas. ${ }^{19}$

\section{O ACIRRAMENTO DO CONFLITO DISTRIBUTIVO NA BASE}

\section{A Segmentação da Assistência: a "Exclusão" da Exclusão}

Esses mecanismos operativos da nova política social geram segmentação e seletividade crescentes entre os genericamente considerados "pobres", "os mais pobres entre os pobres", sedimentando um universo de "excluídos" da proteção social. ${ }^{20}$

Falar em "direito à assistência", de acordo com o instrumento legal de 1993, no Brasil, apenas institucionaliza o princípio restritivo. Lautier (1999), analisando as conseqüências dessa intervenção, mostra que a Lei de Assistência mistura princípios objetivos (ativos preexistentes na forma de terra, competência, residência, etc.) com dados subjetivos (espírito de empresariamento, desejo de ultrapassar as condições de pobreza) para operar a seleção dos que são "dignos" de serem ajudados. Entretanto, excluem-se dos argumentos algumas "necessidades" evidentes dos pobres, de caráter distributivo, como a Reforma Agrária e questões vinculadas à institucionalidade do sistema de previdência, seguro e emprego. Através de um eqüacionamento equivocado que identifica trabalhadores protegidos como "privilegiados”, pelo acesso legítimo aos bens e serviços públicos não disponíveis ao conjunto da sociedade, cria-se um falso problema que induz a um conflito no âmbito das relações das diversas categorias de trabalhadores entre si e dessas com o Estado. ${ }^{21}$

Além dos efeitos que esta segmentação e distorção de sentidos geram no âmbito da construção de uma nação, do ponto de vista das relações entre os cidadãos e o Estado de direitos cria-se, enfim, uma nova estratificação na relação desses com o Estado democrático, tendo em vista as possibilidades "da inclusão", com a seguinte configuração:

- os cidadãos protegidos ("privilegiados");

- os protegidos da assistência garantida pela LOAS;

- os atendidos por programas estruturantes, como a Reforma Agrária, mas dependentes de opções orçamentárias; 
- os parcial e temporariamente assistidos dos programas focalizados;

- uma ampla faixa de "excluídos da assistência, da proteção e do trabalho" que, de fato, forma a grande maioria da "população ajudável" — os no man's land, conforme designação de Lautier (1999) e os desafiliados de Castel (1995): os assalariados precários que perderam os direitos ao seguro; os não-assalariados (autônomos de serviços e comércio instável), incapazes de provar potencial produtivo; os qualificados inativos que não são dignos de integrar os focos assistenciais, pois não são muito pobres ou não são muito velhos; e os eventualmente suspeitos de simulação, os "falsos pobres".

Em relação ao primeiro grupo observa-se uma tendência declinante. De 1980 até hoje, o emprego formal e protegido teve sua participação reduzida de modo continuado, configurando um quadro crescente de precarização da força de trabalho, com a informalidade atingindo, em junho de 2003 , cerca de $60 \%$ da PEA ocupada. A taxa de desemprego, que em termos gerais do país correspondia a $7,15 \%$, registrou, em 2002, taxas bem mais elevadas nas principais áreas metropolitanas, ${ }^{22}$ passando de $12,9 \%$ (março de 2002) para 13\% (junho de 2003), segundo dados da Pesquisa Mensal de Emprego (Ipea, 2003:80).

Este quadro de precarização do mercado de trabalho, associado às ações mitigadoras e compensatórias dos programas focalizados de transferência de renda, ${ }^{23}$ tem efeitos crescentes sobre a demanda de assistência e acesso aos direitos sociais porque não apenas reduz a massa salarial e, portanto, a capacidade de contribuir, mas também amplia a população potencialmente demandante de serviços de assistência social, além de outros aspectos.

A estimativa dessa população compreendia, em 2001, um total de 164,8 milhões de pessoas, expressando um crescimento de $12 \%$ em relação a 1996 , quando representava 147, 5 milhões de pessoas distribuídas diferentemente segundo faixas etárias e regiões do país. ${ }^{24}$

O único segmento populacional que registrou declínio da demanda por assistência, entre 1996 e 2001, com uma redução de $2 \%$, foi aquele das pessoas carentes com 7 a 14 anos, num quadro geral de crescimento da demanda da ordem de $12 \%$. A retração da demanda nesta faixa etária resulta, provavelmente, da ação dos programas sociais direcionados para juventude, especialmente o Bolsa Escola e o Programa de Erradicação do Trabalho Infantil - Peti, Brasil Jovem. ${ }^{25}$

Por um lado, se este declínio pode reforçar a justificativa da focalização, por outro, seus efeitos inclusivos são discutíveis de uma perspectiva longitudinal e intergeracional, quando se observa a taxa de crescimento elevada da demanda da assistência nos segmentos etários posteriores (de 18 a 24 e de 25 a 59 anos). Estes, no mesmo período, apresentaram taxas de crescimento da demanda superiores ao total do Brasil, respectivamente, de $20 \%$ e $17 \%$, indicando claramente que, numa perspectiva temporal e intergeracional, ou seja, ao se analisar a pobreza como processo subordinado à dinâmica do mercado de trabalho, as ações focalizadas têm impacto restrito e apenas adiam e acumulam o problema.

Ademais, a relação entre as metas do atendimento focalizado sobre a demanda potencial são muito restritas, além de contingenciadas pela garantia de verbas. As metas previstas para 2004, em relação à cobertura da Bolsa Família, por exemplo, corresponderá apenas a $9 \%$ da população potencialmente demandante de assistência de 2001.

\section{A TECNIFICAÇÃO DA POLÍ́TICA}

\section{Avaliação da Racionalidade Instrumental da Gestão da Pobreza como Escolha Pública Eficiente}

Esta tese coloca o dilema da questão social no âmbito da "escolha pública eficiente". Segundo essa perspectiva, os recursos governamentais destinados à política social são suficientes, restando apenas serem bem focalizados ou administrados. ${ }^{26}$ Theodoro e Delgado (2003) esclarecem que essa idéia acaba por "embutir uma solução 'barata' para a questão social sobretudo pela redução do esforço fiscal associado".

Observando-se o conjunto das políticas sociais de caráter focalizado aplicadas mais recentemente no Brasil, constata-se, por exemplo, uma redução das metas de muitos desses programas, ${ }^{27}$ em 2002 . Isto é revelador da flexibilidade e vulnerabilidade das políticas públicas, condicionadas pelas incertezas e vulnerabilidade da política econômica nesses países. ${ }^{28}$

O desempenho e a cobertura dos programas focalizados são constantemente redefinidos, levando muitas vezes à redução da cobertura e gerando uma focalização da focalização, à medida que se restringem as áreas de aplicação do programa aos beneficiários mais pobres entre os previamente identificados, criando discriminações involuntárias no atendimento em populações igualmente ou até mais carentes ${ }^{29}$ e acirrando o conflito redistributivo na base da pobreza entre os que acedem e os que não acedem aos benefícios dos programas. 
Ademais, essa vulnerabilidade está condicionada pela base do financiamento desses programas. Analisando-se o comportamento do Fundo Nacional de Assistência Social - FNAS, entre 2002 e 2003, observa-se um decréscimo real de $6,3 \%$, ou seja, de $\mathrm{R} \$ 5,2$ bilhões para $\mathrm{R} \$$ 4,9 bilhões, apesar do acréscimo dos valores nominais de R\$ 200 milhões em 2003. Mesmo observando uma expansão de 6,1\% da Cofins no FNAS, em 2003, esse aumento não foi suficiente para compensar a queda de $12,2 \%$ verificada nos recursos do Fundo de Combate à Pobreza - FCP, com efeito sobre o financiamento dos programas focalizados. O Programa Brasil Jovem, por exemplo, teve a sua dotação reduzida em 58,3\% (Ipea, 2003).

O problema é que as ações focalizadas constituem-se em programas e em acompanhamentos e avaliações, e não em direitos ou em políticas, sendo constantemente afetadas segundo critérios de contingenciamento financeiro ou demandas políticas. Ou seja, o suposto remédio da crise na implantação da "política estratégica focalizada" encontra seus limites no próprio "remédio": a crise do Estado determina a adoção de medidas flexíveis e estratégicas na intervenção social, em razão da vulnerabilidade dos mercados. Essa própria vulnerabilidade, no entanto, é responsável pelos cortes e pela falta de continuidade de muitas das ações desses programas sociais, freqüentemente submetidos à contingência e incerteza da política econômica.

O dilema, portanto, não diz respeito à alocação eficaz do recurso existente, mas sim à recriação de um novo contrato social que tenha como princípio ordenador o Estado social de inclusão prescrito na Constituição de 1988. E esta questão não é técnica, mas sobretudo de política de desenvolvimento do Estado nacional.

\section{A Tese da Transferência de Renda como Base de Acesso à Cidadania: o Consumidor Tutelado}

Sem desconhecer o efeito do alívio que esses programas de transferência de renda possam ter sobre as famílias vulnerabilizadas e desempregadas, a monetarização da assistência tem implicações políticas importantes.

Como mencionado no início desse artigo, não se pode desvincular o desenho das políticas sociais da conformação do mercado de trabalho, principal mecanismo de inclusão social, de sociabilidade e da política, uma vez que a condição de acesso ao trabalho livre define a condição da cidadania.
Na base da monetarização da assistência localiza-se um diagnóstico da crise social como crise de consumo, resultante de políticas em favor da rentabilidade do capital. Desta perspectiva, a defesa dos programas de transferência de renda tem como pressuposto de base a idéia implícita da incapacidade de suprir as necessidades mínimas da inserção via mercado de trabalho. Assim, se o tratamento das políticas voltadas para transferência de renda, por um lado, possibilita algum acesso ao consumo e, portanto, alguma condição de reprodução e inserção social, por outro, reconverte do ponto de vista político "o assistido" em cidadãos-consumidores tutelados dos sistemas de assistência social, elevando o ato da compra a ato cívico.

\section{As Políticas de Proximidade no Enfrentamento da Pobreza}

$\mathrm{Na}$ base desse paradigma das políticas de proximidade encontra-se um diagnóstico da nova questão social que identifica o processo de vulnerabilidade social, entendida pela conjugação entre precarização do trabalho e fragilidade dos suportes relacionais (Castel, 1995) e a idéia de que as redes de solidariedades primárias têm se constituído em capital social importante nas condições de inserção social de camadas populares. Agrega-se a este diagnóstico a noção de uma maior eficácia da geração de projetos de desenvolvimento auto-sustentáveis locais e na operacionalização das políticas sociais no âmbito das políticas sociais descentralizadas e sob o controle da sociedade civil local.

A questão central dessas teses ${ }^{30}$ é que a implementação local da política supõe, por um lado, atores organizados e, por outro, municípios com capacidade institucional de gerenciamento nem sempre compatível com a realidade preexistente da rede de municípios brasileiros. ${ }^{31}$ Efetivamente, dados sobre a aplicação da Lei de Responsabilidade Fiscal no âmbito dos municípios brasileiros revelam que 3.425 deles se encontram com balanços atrasados (Folha de S.Paulo, 15/09/2002). Isto revela, de alguma forma, a fragilidade institucional dos municípios no gerenciamento e operacionalização dos programas sociais. Do ponto de vista da organização dos atores locais, observa-se que a eficácia desses projetos está condicionada à existência de atores organizados e que esta organização não pode estar limitada à esfera das sociedades locais, devido aos riscos de serem capturadas pelas estruturas de poder local. ${ }^{32}$ 
Quanto às variáveis políticas, cabe perguntar: como garantir eficácia das ações de parceria entre público e privado (um dos paradigmas da governança) sob o controle de sociedades civis locais tradicionalmente condicionadas por um Estado patrimonial, que organiza os interesses de muitas elites locais pela privatização de estruturas públicas e institucionais?

Ademais, a focalização não pode encaminhar a solução de problemas estruturais, geradores da vulnerabilidade e da exclusão, próprios da dinâmica econômica nacional, e sobre os quais as instâncias locais não têm poder para solucioná-los ou alterá-los. Na pesquisa de 1997, verificou-se que os ganhos de eficiência de muitos projetos sociais foram anulados pelas obrigatoriedades do pagamento da dívida pública com a União (Ivo, 1997; 2000). Ou seja, existem problemas estruturais que estão longe de serem resolvidos exclusivamente através das ações compensatórias ou das solidariedades primárias e que requerem a construção de políticas mais amplas de geração de emprego e renda. ${ }^{33}$

As saídas econômicas via o desenvolvimento de uma Economia Solidária, por sua vez, estão longe de representar a realidade da economia informal no Brasil. Análise desenvolvida por Borges e Franco (1999), sobre as características do setor informal na Região Metropolitana de Salvador - RMS, ${ }^{34}$ revela que a economia informal, longe de se constituir em matriz societária capaz de estruturar alternativas sólidas de uma economia de base solidária, assentada no trabalho familiar e com alta capacidade de integração ao mercado, representa um grau radicalizado de individualização do trabalho, com características de baixíssima socialização, tais como: predominância de um único trabalhador (o trabalhador autônomo e por conta-própria); baixíssimo nível de constituição jurídica dessas "microempresas"; funcionamento na via pública, revelando não se tratar de um setor organicamente integrado à cadeia produtiva, mas significando, sobretudo, uma estratégia de sobrevivência de trabalhadores precarizados, num contexto de dificuldades de incorporação e de destruição de postos de trabalho da economia formal. As autoras ainda atestam o baixo nível de cobertura dos direitos sociais do segmento dos trabalhadores que integram a economia informal.

Estes argumentos levam a concluir que as teses relativas ao empreendedorismo e ao enfrentamento da pobreza via mercado, estimulados através de estratégias de capacitação ou empowerment desses sujeitos historicamente submetidos às condições estruturais de pobreza, devam ser consideradas com reservas, dada a configuração histórica e excludente dos mercados de trabalho no Brasil.

\section{CONCLUSÃO}

Os dados apresentados revelam processos de exclusão de uma parcela populacional pertencente ao segmento daqueles que estão fora das políticas de proteção, pois não têm empregos e nem renda para a cotização privada e estão fora do mercado, mecanismo central das políticas de integração social.

Entretanto, as políticas compensatórias, ao restringirem sua ação segundo objetivos focalizados, deixam de lado um conjunto de indivíduos efetivamente necessitados, provocando segmentação e seletividade entre os assistidos do Estado, que se localizam entre os que estão fora da proteção e os que estão fora da assistência focalizada, num contexto político democrático que reconhece igualdade de oportunidades e tratamento a todos os cidadãos.

Cria-se, assim, uma "circularidade do social", um fechamento sobre si mesmo, incapaz de mediar a articulação entre os diferentes níveis da estrutura social: o econômico, o social e o político, ou seja, na construção dos vínculos estruturais.

Num contexto de economias abertas e competitivas, postulam-se políticas flexíveis ajustadas às variações do mercado e aos ajustes dos gastos públicos, como critério de eficácia. No âmbito da solução encontrada, de flexibilidade e focalização dos programas, os seus limites situamse na sua própria causa, ou seja, na instabilidade dos mercados e da economia que comprometem a continuidade dos programas. Isso leva a considerar a reprodução de círculos lógicos sem saídas, cujo fechamento restringe efetivamente o êxito desses programas, reduzindo o conflito redistributivo para uma luta entre os pobres e os "quase" pobres.

A dissociação entre políticas sociais aplicáveis a todos e políticas sociais focalizadas dificulta os objetivos cumulativos de combater a pobreza, construir cidadãos e eliminar a exclusão (Fleury, 1998), restringindo a cidadania a uma dimensão parcial do atendimento e do consumo, assegurados pelo estatuto de uma cidadania cívica e segmentando a condição de inserção e a relação desigual dos cidadãos (aqueles atendidos e protegidos e os desassistidos) com o Estado. 


\section{NOTAS}

1. As dimensões da relação entre pobreza e democracia, nas sociedades contemporâneas, e a análise dos dispositivos que orientam as alternativas contemporâneas de recriação das soluções para o encaminhamento da pobreza foram objeto de análise, em livro escrito em 1999 , editado pelo CLACSO em 2001 (Ivo, 2001). Grande parte das teses aqui apresentadas foi extraída deste livro e atualizada em dois artigos, mais recentes (Ivo, 2003a e 2003b).

2. Não falo da crise fiscal diante de demandas insatisfeitas, mas de uma governabilidade democrática e civilizatória, no sentido de o governo atuar para construir a solidariedade nacional.

3. Aproprio-me da expressão usada por Esping-Andersen (1990).

4. Ver a propósito o texto de Jamur (1999), que desenvolve uma análise da construção dos processos institucionais de solidariedade.

5. Não discutirei aqui as questões polêmicas que envolvem os objetivos, os recortes e os alcances da reforma da Previdência, que fogem aos objetivos mais restritos desse artigo. Essa análise deve ser feita a partir da perspectiva mais amplas da capacidade redistributiva da renda, os verdadeiros beneficiários dessa reforma e o que ela contempla em termos de aperfeiçoamentos da justiça social e dos direitos sociais, econômicos e cívicos.

6. Especialmente os regimes especiais do funcionalismo público.

7. Esta reconversão, por exemplo, transforma o tratamento de combate ao desemprego em ações de assistência e não em projetos de inserção incluídos num projeto de desenvolvimento sustentado.

8 . No contexto internacional, desde o final da década de 80 , observase a construção de uma agenda de combate à pobreza nos dispositivos normativos dos documentos do Banco Mundial. No Brasil, este processo ganha centralidade na agenda política do segundo governo de Fernando Henrique Cardoso.

9. Esta afirmação não significa reforçar saídas românticas fora das condições reais e efetivas das contas públicas, mas trata-se de subordinar os gastos às escolhas de prioridades que contemplem a responsabilidade pública de inclusão social e desenvolvimento.

10. Conforme sistematização de Theodoro e Delgado (2003).

11. Previdência básica; SUS - hospitalização e consultas; benefícios e prestações continuadas da LOAS e seguro-desemprego (Ipea, 2003).

12. Programa de Reforma Agrária; projetos estruturantes, como "Fome Zero"; Fundo de Desenvolvimento do Ensino Fundamental - Fundef; Merenda Escolar (Ipea, 2003).

13. Inclui-se aí toda uma variedade de programas focalizados na linha de pobreza, que resolvam demandas legítimas não atendidas nos dois núcleos anteriores.

14. Conforme análise de artigo de Theodoro e Delgado (2003).

15. A perspectiva da organização política dos pobres origina-se de uma perspectiva de desenvolvimento social e humano construída por Amartya Sem, Prêmio Nobel de Economia de 1998, que supere a visão do desenvolvimento ao simples crescimento econômico. Esta perspectiva induziu transformar os pobres de um "sujeito passivo", beneficiário de planos sociais para "sujeito ativo", protagonista da mudança social. Esta abordagem, que envolve o desenvolvimento de capacidades estratégicas e orientou os relatórios do PNUD, tem sido reapropriada com diferentes sentidos segundo diversos atores políticos e sociais. Uma análise sobre esses diferentes sentidos foi apresentado em Ivo (2001: cap.III; 2003a; 2003b).

16. Não se desconhecem aqui alguns efeitos positivos dos programas de transferência de renda sobre os beneficiários, sobretudo sua eficácia no estímulo ao consumo. Entretanto, acredita-se que os esforços distributivos mais efetivos situam-se na centralidade dos programas universais e inclusivos no âmbito da saúde, da previdência, do trabalho, da reforma agrária, etc.
17. A referência aqui é aos novos pobres, com impossibilidade de inclusão e perda das perspectivas coletivizadas no encaminhamento da política da questão da inserção, num quadro de desregulação da proteção social.

18. Nesta linha muitas teses têm sido desenvolvidas em termos da economia solidária e da transformação dos cidadãos em "consumidores".

19. Ver sobre governabilidade Ivo (2001: cap. II). Esta ruptura leva à construção, por parte de muitos atores, de que os pobres foram relegados à sua própria sorte.

20. Os no man's land, segundo Lautier (1999).

21. Esses privilegiados seriam os trabalhadores protegidos pela legislação trabalhista e com acesso ao sistema previdenciário, os trabalhadores rurais com direito à previdência rural e, especialmente, os funcionários públicos dotados de regime especial (Theodoro; Delgado, 2003).

22. Recife, Salvador, Belo Horizonte, Rio de Janeiro, São Paulo e Porto Alegre.

23. A população atendida pelos programas de transferência de renda correspondeu a um total de 3,7 milhões de famílias na Bolsa Escola; 810 mil crianças no Programa de Erradicação do Trabalho Infantil - Peti, 326 mil famílias com Bolsa Alimentação; 349 mil no Cartão Alimentação e 6,9 milhões do Auxílio-Gás em 2003. Tentando racionalizar o processo de transferência de renda para a população carente, o governo lançou em fins de 2003 o Bolsa Família (associado aos programas de Bolsa Escola, Auxílio-Gás, Cartão Alimentação e Vale-Refeição), que contemplou 3,6 milhões de famílias, com um benefício médio de R \$73,00/ família. Para 2004, o governo prevê ampliar sua ação na área metropolitana e chegar a uma cobertura de 4,5 milhões de famílias, o que equivale a atender cerca de 15 milhões de pessoas carentes.

24. Conforme dados extraídos do Ipea (2003:80-81).

25. Não há evidência direta dessa relação no âmbito desse artigo, mas a suposição se baseia na prioridade que os programas focalizados tiveram para esta faixa de idade e também a sua maior cobertura, especialmente quanto às metas do Peti (ainda que sua população total seja bem mais reduzida).

26. A partir dessa avaliação aponta-se um conjunto de recomendações importantes mas não suficientes, como o combate ao clientelismo, maior direcionamento dos recursos às atividades-fins, diminuindo os custos das transações, etc. (ou seja, um conjunto de recomendações normativas do "bom governo", desde fins da década de 80 recomendadas pelas agências multilaterais), maior integração e racionalidade institucional do próprio sistema federal e medidas de eficácia à descentralização, etc.

27. Segundo dados publicados pela Folha de S.Paulo, 26/05/2002, a Bolsa-Alimentação projetava um número de beneficiários da ordem de 1.623 .000 enquanto só atendeu, efetivamente, 208.000 beneficiados; a Bolsa-Escola previa atender um total de 10.195.000 crianças e atendeu 8.526.002; a implantação do Vale-Gás projetava um total de 9.300 .000 beneficiários em 2002 e, até maio daquele ano, havia beneficiado pouco mais da metade da meta prevista, ou seja, 4.996.634 famílias. Dos programas sociais focalizados, aquele que havia cumprido as metas previstas em 2002 foi o Peti, que projetou um total de 813.000 beneficiários, tendo beneficiado 801.714 famílias (maio de 2002), apesar de também ter sofrido reduções de gastos e readequação das metas desse Programa.

28. No que pese reconhecer os limites desses programas, especialmente em relação à universalidade da cobertura dos benefícios e à necessidade e dependência de políticas de crescimento macro-estruturais de emprego e renda, não se pode deixar de reconhecer que a atuação do Programa tenha melhorado as condições de reprodução das famílias beneficiadas, ainda que não as tenha retirado da condição de pobreza. Prova disto é o aumento da população carente nas faixas etárias da população adulta, anteriormente mostrado. 
29. Recentemente, um chefe de família ouvido sobre a prioridade inicial do Programa Fome Zero do governo federal, que vive em situação de indigência, mas morador de uma região que apresenta indicadores de desenvolvimento humano mais elevados, mostrava sua indignação quanto ao fato (injusto) de não ter sido contemplado pelos critérios iniciais de implantação do Programa.

30. O termo está no plural porque inclui-se, nesta linha, um conjunto de princípios normativos ou mesmo institucionais de desenvolvimento local: local governance; capital social; desenvolvimento auto-sustentado; etc.

31. Lavinas (1998), em paper apresentado à Anpocs sobre a capacidade dos municípios brasileiros de absorver essa política, demonstra que apenas 5\% deles têm condições de implementar plenamente políticas de renda mínima, dada sua pobreza econômica e conseqüente insuficiência da arrecadação e do aparato institucional local.

32. Numa pesquisa sobre os limites da governança, desenvolvida em 1997, observou-se que os resultados desses programas estavam condicionados pela força dos atores sociais envolvidos e pela extensão da rede de solidariedade de sua sustentação, resultando em segmentação, tecnificação dos processos democráticos de participação cidadã e na idéia de arenas públicas nominais e vazias no contexto da formação de "consensos mínimos e relativos", incapazes de construir solidariedades mais amplas (Ivo, 1997; 2000).

33. Ver o texto de Ivo (2003c).

34. Com base na pesquisa realizada pelo IBGE (1997).

\section{REFERÊNCIAS BIBLIOGRÁFICAS}

BORGES, A.; FRANCO, A. Economia informal da RMS: verdades e mitos. Bahia. Análise e Dados. Salvador, SEI, v.9, n.3, p.68-89, 1999.

CANDIA, J.M. Exclusion y pobreza. La focalizacion de las politicas sociales. Nueva Sociedad. Caracas, n. 156, p.116-126, jul./ago. 1998.

CASTEL, R. Les métamorphoses de la question sociale. Une chronique du salariat. Paris: Fayard, 1995.

DONZELOT, J. L'invention du social. Paris: Fayard, 1994.

ESPING-ANDERSEN, G. The three worlds of welfare capitalism. Cambridge University Press, 1990.

EWALD, F. L'État providence. Paris: Grasset, 1986.

FLEURY, S. Politica social, exclusion y equidad en America Latina en los 90. Nueva Sociedad. Caracas, n.156, p.72-94, jul./ago. 1998.
IBGE. Economia informal urbana: Brasil e grandes regiões. Rio de Janeiro, v.3, 1997.

IPEA. Anexo Estatístico. Políticas sociais: acompanhamento e análise. Brasília, DF, ago. 2003.

IVO, A.B.L. Políticas sociais de combate à pobreza nos anos 1990: novas teses, novos paradigmas. In: SEI - Superintendência de Estudos Econômicos e Sociais da Bahia. Pobreza e desigualdades sociais. Salvador, 2003a. (Série Estudos e Pesquisas, 63).

As novas políticas sociais de combate à pobreza na América Latina: dilemas e paradoxos. In: SEMINÁRIO INTERNACIONAL O PAPEL DO ESTADO NA LUTA CONTRA A POBREZA. Recife: CLACSO/CROP/FJN, mar. 2003b.

Democracia, desigualdades e capital social. In: SCHIMIDT, B. (Org.). Integração, identidade e capital social. Brasília: Editora da UnB, 2003c (prelo).

Metamorfoses da questão democrática: governabilidade e pobreza. Buenos Aires: Clacso/Asdi, 2001.

et al. O poder da cidade. Limites da governança urbana. Salvador-Bahia: EDUFBA, p.201-242, 2000.

Uma racionalidade constrangida: a experiência da governança urbana em Salvador. Caderno $C R H$. Salvador: EDUFBA/ CRH, n.26/27, p.107-145, jan./dez. 1997.

JAMUR, M. Solidariedade(s). O social em questão. Rio de Janeiro, v. 3, n.4, p.25-60, jul./dez. 1999.

LAUTIER, B. Les politiques sociales en Amérique Latine. Propositions de méthode pour analyser un éclatement en cours. Cahiers des Amériques Latines. Paris, n.30, p.19-44, 1999.

LAVINAS, L. Políticas sociais descentralizadas: limites dos programas de renda mínima e bolsa escola. In: ENCONTRO NACIONAL DA ANPOCS, 22. Anais... Caxambu, Anpocs, 1998.

ROSANVALLON, P. La nouvelle question sociale. Répenser l'État Providence. Paris: Le Seuil, 1995.

THÉRET, B. Régimes économiques et l'ordre politique. Paris: PUF, 1992.

THEODORO, M.; DELGADO, G. Política social: universalização ou focalização - subsídios para o debate. Políticas sociais: acompanhamento e análise. Brasília, Ipea, DF, n.7, ago. 2003.

Anete Brito Leal Ivo: Socióloga, Pesquisadora do CRH, Professora participante do Programa de Pós-Graduação em Ciências Sociais da UFBA; Pesquisadora associada do Credal-CNRS-Fr. Foi Professora Visitante da Universidade de Paris III na Cátedra Simon Bolivar (2000). 